\title{
Preparation and characterization of biopolymers comprising chitosan-grafted-ENR via acid-induced reaction of ENR50 with chitosan
}

\author{
M. R. H. Mas Haris ${ }^{1}$, G. Raju $u^{1,2}$ \\ ${ }^{1}$ School Chemical Sciences, Universiti Sains Malaysia 11800 Minden, Penang, Malaysia \\ ${ }^{2}$ Malaysian Rubber Board, 1458 Jalan Ampang, 50450 Kuala Lumpur, Malaysia
}

Received 20 July 2013; accepted in revised form 26 September 2013

\begin{abstract}
This paper describes the first detailed tailored-approach for the preparation of biopolymers comprising chitosan (CTS) grafted onto the backbone of epoxidized natural rubber (CTS-g-ENR). In a typical experiment, appropriate amount of CTS and $\mathrm{AlCl}_{3} \cdot 6 \mathrm{H}_{2} \mathrm{O}$ was added to a specified amount of ENR50 (ENR with about $50 \%$ epoxy content) dissolved in a dual-solvent consisting of 1,4-dioxane and water $(97.5: 2.5 \% \mathrm{v} / \mathrm{v})$ and the resulting mixture refluxed with continuous stirring for 6 hours. Nuclear magnetic resonance (NMR) spectral analysis of a biocomposite, CTS-g-ENR-P1, revealed that its epoxy content is $22.36 \%$ which is considerably lower than $44.93 \%$ as determined for ENR50-control (ENR50 derivative obtained under similar experimental condition but in the absence of CTS). This means that the grafting of CTS onto the backbone of ENR had occurred. The revelation is affirmed by the presence of the characteristic absorption bands of CTS and ENR, and the appearance of new bands at 1219, 902 and $733 \mathrm{~cm}^{-1}$ in the Fourier transform infrared (FTIR) spectrum of CTS-g-ENR-P1. Further evidence that CTS had been successfully grafted onto the backbone of ENR can be deduced and described in this paper from the data obtained by means of Differential Scanning Calorimetric analysis, Thermogravimetric analysis and Variable Pressure Scanning Electron Microscopy.
\end{abstract}

Keywords: biopolymers, chitosan, epoxidized natural rubber

\section{Introduction}

Chitin is a linear biopolymer and the second most abundant natural polysaccharide after cellulose [1]. The usual commercially available chitin is typically extracted from crab and shrimp shells. Chitosan is derived from chitin [2]. It is composed of predominantly $\alpha(1 \rightarrow 4)$-linked 2 -amino-2-deoxy- $\beta$-D-glucopyranose with some amount of, 2-acetamido-2deoxy-D-glucopyranose sugars, depending on the degree of N-deacetylation [3-5]. Due to the presence of the primary amino (C-2), primary (C-6) and secondary (C-3) hydroxyl groups on each repeat unit, chitosan is indeed a multinucleophilic material that may undergo specific reaction with other materials that contain electrophilic sites. Chitosan is being used in a wide range of applications ranging from biomedical engineering, pharmaceutical and cosmetic products to water treatment and plant protection [6]. Being a natural polysaccharide, chitosan exhibits high biodegradability but have poor mechanical properties. As such, modification of polymers that possess excellent thermal and mechanical parameters with chitosan may result in the production of a new class of polymeric materials exhibiting not only desired biodegradability but also good physicochemical and mechanical properties [7].

Incorporation of chitosan in the matrices of elastomers is of interest to researchers in areas that

\footnotetext{
${ }^{*}$ Corresponding author, e-mail: mas1@usm.my

(C) BME-PT
} 
involve the utilization of natural rubber or its derivatives and chitosan [8-16]. Of special interest to our current work, Lertwattanaseri et al. [13] reported the preparation of a novel model case of bionanocomposites comprising nanofibrous chitosan bonded to the backbone of epoxidized natural rubber (ENR) via both amino and hydroxyl groups. Confirmation of the proposed structure for the ENR-chitosan bionanocomposite was done by qualitative and quantitative FTIR techniques. Considering the nature of the reactivity of the hydroxyl and amino groups of chitosan, we believe the proposed structure is inconclusive. Very recently, Riyajan and Sukhlaaied reported the preparation of ENR-g-chitosan involving the reaction of chitosan radicals with ENR molecules using potassium persulphate $\left(\mathrm{K}_{2} \mathrm{~S}_{2} \mathrm{O}_{8}\right)$ as an initiator [16]. The chemical structure of the ENR-g-chitosan, specifically the presence of ether linkage in the biopolymers, was confirmed by ${ }^{1} \mathrm{H}-\mathrm{NMR}$ and ATRFTIR.

Chitosan is soluble in acidic aqueous media $[17,18]$ whereas ENR, being hydrophobic in nature, is not [19]. This is the likely reason why there is very limited number of reports in the literature on homogenous (liquid-liquid phase) or semi-heterogeneous (liquid-solid phase) reaction condition involving chitosan and ENR. Furthermore, ENR is known to undergo ring-opening and double bond cleavage reactions [20-25]. To date, there is no report on the stability of the microstructure of ENR in conditions with different concentrations of acid. In view of this finding and as part of our interest to gain further insights on the physicochemical and mechanical properties of natural rubber latex films that were subjected to acid and/or base treatments [26-27], we have carried out the study on the effect of acidity on the stability of the molecular structure of ENR50. We found by means of NMR spectroscopy that the epoxidized isoprene units of ENR50 did not undergo significant ring-opening reaction in 1,4-dioxane acidified by the addition of dilute $\mathrm{HCl}$ or $\mathrm{AlCl}_{3} \cdot 6 \mathrm{H}_{2} \mathrm{O}$ solution. This observation prompted us to investigate and hereby report our findings on the acidinduced reaction of ENR50 with chitosan.

\section{Experimental}

\subsection{Materials}

Epoxidized natural rubber with about 50\% epoxy content (designated as ENR50) and with relative
$M_{\mathrm{w}}$ of $3.8 \cdot 10^{5} \mathrm{~g} / \mathrm{mol}$ was supplied by Malaysian Rubber Board, Kuala Lumpur, Malaysia. Chitosan (CTS) with with relative $M_{\mathrm{w}}$ of $1.0 \cdot 10^{5} \mathrm{~g} / \mathrm{mol}$ was provided by Advanced Materials Research Centre at Kulim, Kedah, Malaysia. The degree deacetylation of the CTS was determined by a titration method [28] and found to be $96 \%$. $\mathrm{HCl}$ and $\mathrm{AlCl}_{3} \cdot 6 \mathrm{H}_{2} \mathrm{O}$ (purchased from Merck, Damstardt, Germany), 1,4-dioxane (Fisher, Malaysia) and $\mathrm{NaOH}$ (System Chemar) were used as received. Deuterated chloroform (Merck, $99.8 \%$ with $0.03 \%$ TMS) was used as the NMR solvent.

\subsection{Instruments}

${ }^{1} \mathrm{H}-\mathrm{NMR}$ spectra of samples dissolved in $\mathrm{CDCl}_{3}$ were recorded on a Bruker Avance-400 NMR spectrometer operating at $400.13 \mathrm{MHz}$. Tetramethylsiloxane (TMS) was used as the internal reference. Infrared spectra were recorded using a Perkin- Elmer 2000 Infrared Spectrometer with 16 scans at $4 \mathrm{~cm}^{-1}$ resolution. Solid ENR50 and CTS-g-ENR biopolymers were analysed directly using an attenuated total reflection (ATR) technique within the wave number range of $4000-650 \mathrm{~cm}^{-1}$. CTS was analyzed in the form of $\mathrm{KBr}$ pellet ( $\mathrm{KBr}$ : $\mathrm{CTS}=98: 2)$ within the wave number range of 4000 to $400 \mathrm{~cm}^{-1}$. Differential Scanning Calorimetry (DSC) analysis was carried out using Perkin-Elmer Pyris-1 DSC, equipped with an internal cooler 2P-cooling accessory and calibrated using n-decane and indium. Samples (5$10 \mathrm{mg}$ ) were examined within an atmosphere of dry nitrogen gas maintained at a flow rate of $50 \mathrm{~mL} / \mathrm{min}$. All samples were annealed at a heating rate of $20^{\circ} \mathrm{C} / \mathrm{min}$ (for both heating and quenching). For the first scan, samples were heated from $-50^{\circ} \mathrm{C}$ up to at least $100^{\circ} \mathrm{C}$ and hold for about 2 minutes before cooling (at $20^{\circ} \mathrm{C} / \mathrm{min}$ ) back to $-50^{\circ} \mathrm{C}$. The second scan was performed after 2-5 minutes of waiting time. Thermal weight loss measurements were made using Perkin-Elmer TGA-7 thermogravimetric analyser. Testing was carried out under a stream of dry nitrogen gas (flow rate $=30 \mathrm{~mL} / \mathrm{min}$ ) at temperature range of 40 to $600^{\circ} \mathrm{C}$ with heating rate of $10^{\circ} \mathrm{C} / \mathrm{min}$. Weight of samples used was within 4 $10 \mathrm{mg}$. Data of Variable Pressure Scanning Electron Microscopy (VPSEM) was obtained with the use of Carl Zeiss EVO LS 10 Scanning Electron Microscope. The morphology of the ENR50, CTS and CTS-g-ENR biopolymers were studied. 


\subsection{Methods}

\subsubsection{Exposure of ENR50 to different concentrations of $\mathbf{H C l}$ or $\mathrm{AlCl}_{3} \cdot 6 \mathrm{H}_{2} \mathrm{O}$}

ENR50 (1.0 g) was dissolved in $95 \mathrm{~mL}$ 1,4-dioxane at room temperature inside a $250 \mathrm{~mL}$ two-necked round bottom flask equipped with a magnetic stirrer and a reflux condenser. Then $5 \mathrm{~mL}$ of $0.0001 \mathrm{M} \mathrm{HCl}$ was added dropwise and the resulting solution stirred for 4 hours. A sample of the solution $(10 \mathrm{~mL})$ was isolated every hour and placed in about $10 \mathrm{~mL}$ of chilled $0.0001 \mathrm{M}$ sodium hydroxide to neutralize and precipitate the resulting ENR50 derivative. This derivative was isolated and washed with ample amount $(>200 \mathrm{~mL})$ of distilled water. Then it was placed in an oven with the temperature maintained at $50^{\circ} \mathrm{C}$ for 24 hours. The procedure was repeated but with the use of $0.001 \mathrm{M}, 1.0 \mathrm{M}$ and $3.0 \mathrm{M} \mathrm{HCl}$. All resulting polymeric materials were analysed by NMR spectroscopy.

The experiment was repeated with the use of 0.75 and $0.30 \mathrm{~g}$ of aluminium chloride hexahydrate $\left(\mathrm{AlCl}_{3} \cdot 6 \mathrm{H}_{2} \mathrm{O}\right)$ in lieu of $\mathrm{HCl}$. ENR50 derivatives obtained after been exposed to $\mathrm{AlCl}_{3} \cdot 6 \mathrm{H}_{2} \mathrm{O}$ for 2,4 and 24 hours were analysed by NMR spectroscopy.

\subsubsection{Reaction of chitosan with ENR50 in acidified 1,4-dioxane}

ENR50 (1.0 g) was dissolved in a dual-solvent consisting of water and 1,4-dioxane $(2.5: 97.5 \% \mathrm{v} / \mathrm{v})$ inside a $250 \mathrm{~mL}$ two-necked round bottom flask equipped with a magnetic stirrer and a reflux condenser. Then CTS $(1.0 \mathrm{~g})$ and $\mathrm{AlCl}_{3} \cdot 6 \mathrm{H}_{2} \mathrm{O}(0.75 \mathrm{~g})$ were added and the content of the flask was refluxed with continuous stirring for 6 hours. Subsequently, the resulting mixture was cooled and filtered. The filtrate containing the product was concentrated under reduced pressure using a rotary evaporator and cast on a glass plate. The product (CTS-g-ENR-P1) was dried in an oven $\left(50^{\circ} \mathrm{C}\right)$ for 24 hours.

The experiment was repeated with the use of a lower concentration (i.e. $0.30 \mathrm{~g}$ ) of $\mathrm{AlCl}_{3} \cdot 6 \mathrm{H}_{2} \mathrm{O}$. The product obtained is designated as CTS-g-ENR-P2. For the purpose of obtaining a reference sample (ENR50control), ENR50 was subjected to similar reaction condition with the use of $0.75 \mathrm{~g}$ of $\mathrm{AlCl}_{3} \cdot 6 \mathrm{H}_{2} \mathrm{O}$ but in the absence of CTS. All resulting polymeric materials were characterized by means of FT-NMR, FTIR, SEM, DSC and TGA techniques.

\section{Results and discussion}

\subsection{Effect of acidity on the stability of the molecular structure of ENR50}

${ }^{1} \mathrm{H}-\mathrm{NMR}$ spectra of ENR50 and ENR50 derivatives that were obtained after ENR50 been exposed to $0.0001,0.001,1.0$ and $3.0 \mathrm{M}$ of $\mathrm{HCl}$ for 1 hour are depicted in Figure 1. The epoxy group of an epoxidized natural rubber is known to be randomly distributed on the backbone of the polymer. Nonetheless, a fairly comprehensive characterization of the structure of liquid epoxidized natural rubber by means of 1D-NMR and 2D-NMR spectroscopy is available in the literature [29]. For simplicity, the proton resonances of ENR50 as observed in Figure 1 are assigned to a simplified structure depicted in Figure 2 as follows: methyl protons bonded to the epoxidized isoprene unit $\underline{\mathbf{a}}\left(-\mathrm{CH}_{2}-\mathrm{CH}_{3} \mathrm{COCH}-\mathrm{CH}_{2}-\right)=1.29 \mathrm{ppm}$; methylene protons bonded to the epoxidized isoprene unit $\underline{\mathbf{b}}\left(-\mathrm{CH}_{2}-\mathrm{CH}_{3} \mathrm{COCH}-\mathrm{CH}_{2}-\right)=1.55 \mathrm{ppm}$, methyl protons bonded to the isoprene unit $\underline{\mathbf{c}}$

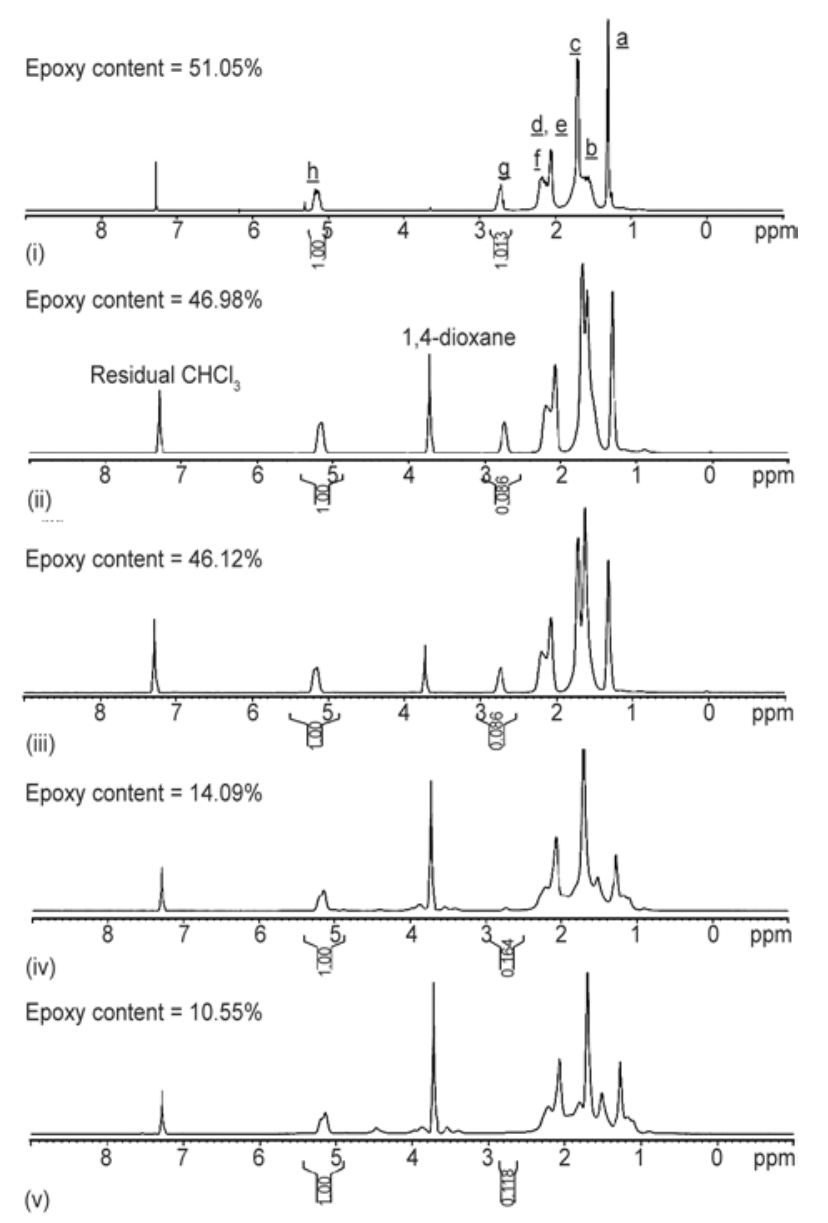

Figure 1. ${ }^{1} \mathrm{H}-\mathrm{NMR}$ spectra of (i) ENR50 and its derivatives obtained after ENR50 has been exposed (ii) $0.0001 \mathrm{M}$, (iii) $0.001 \mathrm{M}$, (iv) $1.0 \mathrm{M}$ and (v) $3.0 \mathrm{M}$ of $\mathrm{HCl}$ for 1 hour 


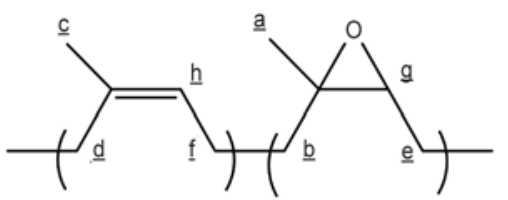

Figure 2. A simplified structure of ENR50

$\left(-\mathrm{CH}_{2}-\mathrm{CH}_{3} \mathrm{C}=\mathrm{CH}-\mathrm{CH}_{2}-\right)=1.67 \mathrm{ppm}$, methylene protons bonded to the isoprene unit $\underline{\mathbf{d}}\left(-\mathrm{CH}_{2}-\mathrm{CH}_{3}\right.$ $\mathrm{COCH}-\mathrm{CH}_{2}-$ ) overlapped with the methylene protons bonded to the epoxidized isoprene unit $\underline{\mathbf{e}}$ $\left(-\mathrm{CH}_{2}-\mathrm{CH}_{3} \mathrm{COCH}-\mathrm{CH}_{2}-\right)=2.04 \mathrm{ppm}$; methylene protons bonded to the isoprene unit $\underline{\mathbf{f}}\left(-\mathrm{CH}_{2}-\mathrm{CH}_{3}\right.$ $\left.\mathrm{COCH}-\mathrm{CH}_{2}-\right)=2.15 \mathrm{ppm}$; methine proton bonded to the epoxidized isoprene unit $\mathbf{g}\left(-\mathrm{CH}_{2}-\mathrm{CH}_{3} \mathrm{COCH}-\right.$ $\left.\mathrm{CH}_{2}-\right)=2.70 \mathrm{ppm}$; methine proton bonded to the isoprene unit $\underline{\mathbf{h}}\left(-\mathrm{CH}_{2}-\mathrm{CH}_{3} \mathrm{C}=\mathrm{CH}-\mathrm{CH}_{2}-\right)=5.10 \mathrm{ppm}$. The presence of residual amount of 1,4-dioxane and chloroform can be observed at 7.16 and $3.70 \mathrm{ppm}$. The epoxy content [30] can be determined with the use of Equation (1):

Epoxy content $=\frac{A_{2.7}}{A_{2.7}+A_{5.1}} \cdot 100 \%$

where $A_{2.7}$ and $A_{5.1}$ refer to the integral area of $\mathbf{g}=$ 2.7 and $\underline{\mathbf{h}}=5.1$, respectively. From Figure 1(i), the actual epoxy content of ENR50 is determined to be $51.05 \%$ whereas that of the ENR50 derivatives (Figure 1(ii)-1(v)) obtained after ENR50 having been exposed to $0.0001,0.001,1.0$ and $3.0 \mathrm{M} \mathrm{HCl}$ is $46.98,46.12,14.09$ and $10.55 \%$, respectively. The effect of acidity on the stability of the molecular structure of ENR50 becomes clear when we consider the degree of reduction of its epoxy content. The difference in epoxy content of ENR50 and that of the ENR50 derivative obtained after having been exposed to 1.0 and $3.0 \mathrm{M} \mathrm{HCl}$ is 36.96 and $40.50 \%$, respectively. However, when in 0.0001 and $0.001 \mathrm{M}$ the difference is only 4.07 and $4.93 \%$, respectively. This means the molecular structure of ENR50 remained fairly intact at low acid concentration $\left(\left[\mathrm{H}^{+}\right] \leq 0.001 \mathrm{M}\right)$ even though its epoxidized isoprene units were likely to be fully protonated and susceptible to undergo ring-opening reaction with nucleophiles.

\subsection{Effect of $\mathrm{AlCl}_{3} \cdot 6 \mathrm{H}_{2} \mathrm{O}$ on the epoxidized isoprene unit of ENR50}

A solution containing $\mathrm{AlCl}_{3} \cdot 6 \mathrm{H}_{2} \mathrm{O}$ is mildly acidic $(\mathrm{pH}=4.5)$ due to the formation of hydronium ion as illustrated by the Brønsted-Lowry acid-base reac-

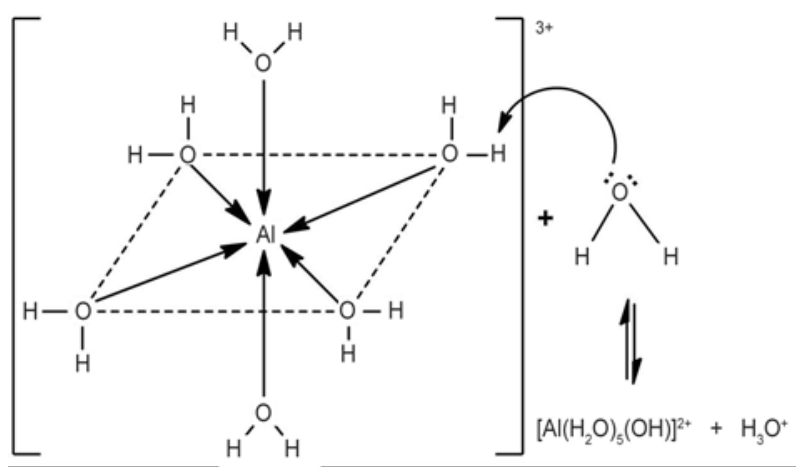

Figure 3. Acid hydrolysis of aluminium ion

tion in Figure 3. When $\mathrm{AlCl}_{3} \cdot 6 \mathrm{H}_{2} \mathrm{O}$ dissolved in water, the aluminium ion will be surrounded with six water molecules. The $\mathrm{Al}^{3+}$ aqua complex ion, $\left[\mathrm{Al}\left(\mathrm{H}_{2} \mathrm{O}\right)\right]^{3+}$, is a weak Brønsted-Lowry acid that donates a proton, $\mathrm{H}^{+}$, forming the $\mathrm{Al}^{2+}$ aqua complex ion, $\left[\mathrm{Al}\left(\mathrm{H}_{2} \mathrm{O}\right)_{5} \mathrm{OH}\right]^{2+}$, whereas the water molecule acts as a weak Brønsted-Lowry base that accepts the proton forming the hydronium ion, $\mathrm{H}_{3} \mathrm{O}^{+}$.

${ }^{1} \mathrm{H}-\mathrm{NMR}$ spectra of ENR50 derivatives that were obtained after ENR50 having been exposed to $\mathrm{AlCl}_{3} \cdot 6 \mathrm{H}_{2} \mathrm{O}$ for 2, 4 and 24 hours are depicted in Figure 4 . Their corresponding epoxy content is determined to be $44.93,44.04$ and $38.84 \%$, respectively. In keeping with the above finding wherein diluted $\mathrm{HCl}$ was used, the epoxidized isoprene units of



Figure 4. ${ }^{1} \mathrm{H}-\mathrm{NMR}$ spectra of ENR50 derivatives obtained after ENR50 has been exposed to $\mathrm{AlCl}_{3} \cdot 6 \mathrm{H}_{2} \mathrm{O}$ for (i) $2 \mathrm{hr}$, (ii) $4 \mathrm{hr}$ and (iii) $24 \mathrm{hr}$ 
ENR50 did not undergo significant ring-opening reaction even though being likely fully protanated in a solution containing $\mathrm{AlCl}_{3} \cdot 6 \mathrm{H}_{2} \mathrm{O}$.

\subsection{Nuclear magnetic resonance spectral analysis}

Figure 5 depicts the fourier transformed ${ }^{1} \mathrm{H}-\mathrm{NMR}$ spectra of ENR50-control and CTS-g-ENR-P1. The epoxy content of ENR50-control and CTS-g-ENR$\mathrm{P} 1$ is determined to be 44.93 and $22.36 \%$, respectively. It is therefore evident that ENR50 underwent a substantial reduction in epoxy content only in the presence of CTS. As such, it is reasonable to deduce that the grafting of CTS onto the backbone ENR50 had likely occurred via ring-opening reaction of protonated epoxidized isoprene units. The plausible reaction pathways leading to the formation of CTSg-ENR biopolymers is discussed later in the text.

\subsection{Infrared spectral analysis}

Figure 6 shows the Fourier transform infrared spectra of ENR50, CTS and CTS-g-ENR-P1. The characteristic vibrational absorption bands of ENR50: 2961, 2923 and $2856 \mathrm{~cm}^{-1}$ are due to C-H stretchings of the $-\mathrm{CH}_{3}-$ and $-\mathrm{CH}_{2}-$ groups, $1660 \mathrm{~cm}^{-1}$ is due the $\mathrm{C}=\mathrm{C}$ stretching, 1448 and $1376 \mathrm{~cm}^{-1}$ are due to $\mathrm{C}-\mathrm{H}$ bendings of the $-\mathrm{CH}_{2}-$ and $-\mathrm{CH}_{3}-$ groups, 1259 and $1018 \mathrm{~cm}^{-1}$ are due to $\mathrm{C}-\mathrm{O}-\mathrm{C}$ stretching and bending of the epoxy group, $873 \mathrm{~cm}^{-1}$ is due to $\mathrm{C}-\mathrm{H}$ bending attached to the epoxy group and $837 \mathrm{~cm}^{-1}$ is due to $\mathrm{C}-\mathrm{H}$ bending attached to the unsaturated carbon [31]. The characteristic bands of CTS: broad band at $3600-3100 \mathrm{~cm}^{-1}$ are due to a combination of $\mathrm{O}-\mathrm{H}$ and $\mathrm{N}-\mathrm{H}$ stretchings of the hydroxyl and primary amine groups, $2956 \mathrm{~cm}^{-1}$ is due to the $\mathrm{C}-\mathrm{H}$ stretching of the $-\mathrm{CH}_{2}-$ group, 1638 and $1560 \mathrm{~cm}^{-1}$ (overlapped) are due to the $\mathrm{N}-\mathrm{H}$ bendings of the amide and primary amine groups, broad band at $1080-1033 \mathrm{~cm}^{-1}$ is due the skeletal vibration involving $\mathrm{C}-\mathrm{O}$ stretching, $896 \mathrm{~cm}^{-1}$ is due the stretching of $\mathrm{C}-\mathrm{O}-\mathrm{C}$ linkage [32]. For CTS-gENR-P1 (Figure 6(iii)), the normally broad band due to the absorption of hydroxyl and amino groups became narrower and shifted to a lower frequency, centered at about $3322 \mathrm{~cm}^{-1}$, indicating that chemical reaction had taken place predominantly at the primary amine rather than at the hydroxyl groups. The considerable reduction of the intensity of the band at $873 \mathrm{~cm}^{-1}$ suggests that the epoxy group was involved in the reaction. The presence of the characteristic absorption band at $1645 \mathrm{~cm}^{-1}$ due to the $\mathrm{N}-\mathrm{H}$ bending suggests that the primary amine group of chitosan was involved in the reaction. Furthermore, the appearance of additional bands at 733 , 902 and $1219 \mathrm{~cm}^{-1}$ assignable to $\mathrm{N}-\mathrm{H}$ wag, C-N bond and saccharide structure of chitosan, respectively [33], affirms that CTS-g-ENR-P1 was produced likely via the acid-induced attack of the primary amine of the former on the epoxide ring of the latter.

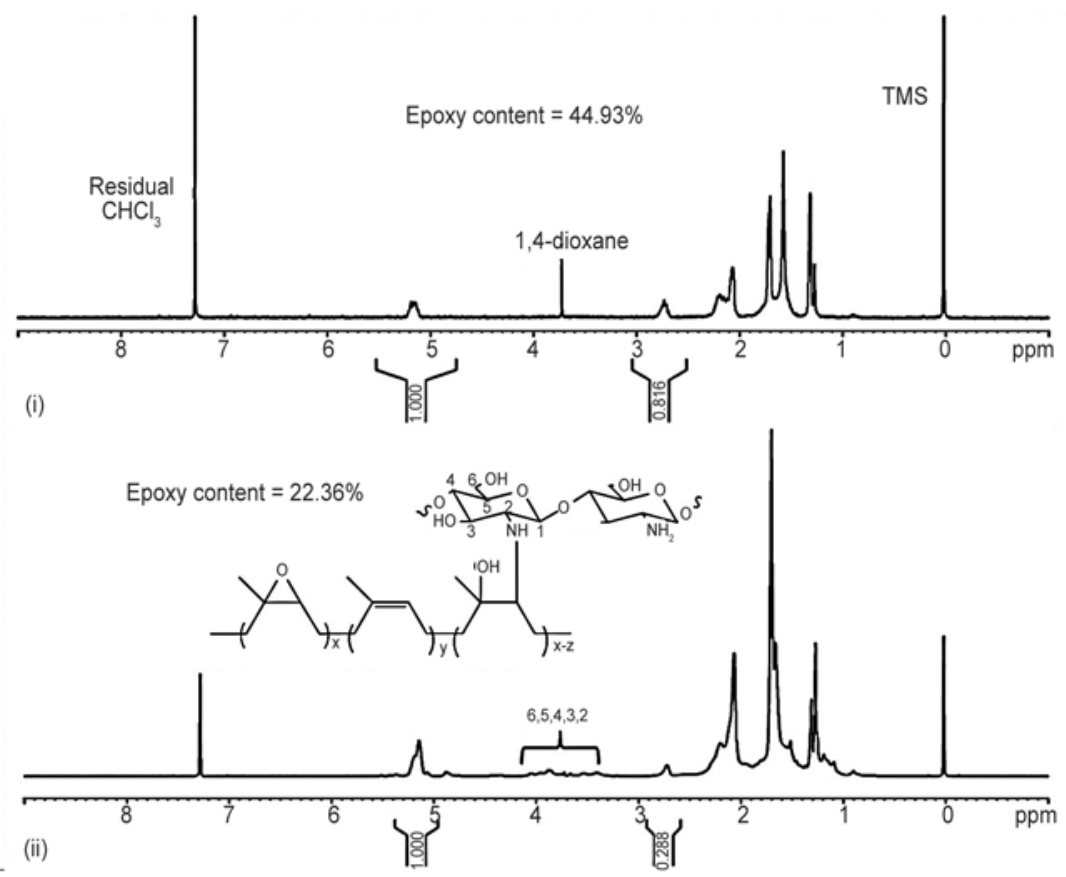

Figure 5. ${ }^{1} \mathrm{H}-\mathrm{NMR}$ spectra of (i) ENR50-control and (ii) CTS-g-ENR-P1 


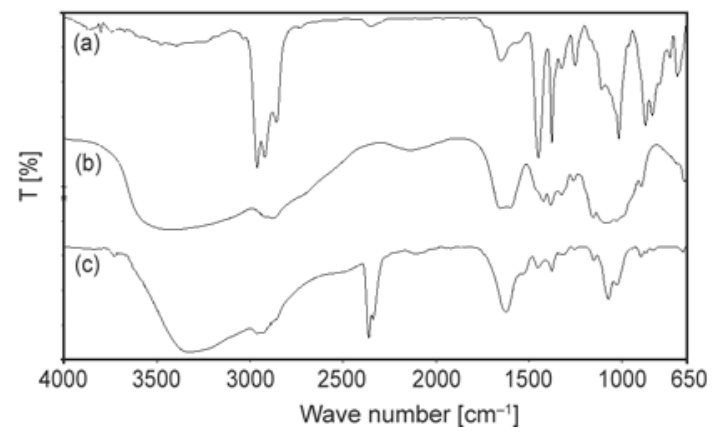

Figure 6. FTIR spectra of (i) ENR50, (ii) CTS and (iii) CTS-g-ENR-P1

\subsection{Differential scanning calorimetric analysis}

The thermograms (DSC second run curves) of CTS/ ENR50-control, CTS-g-ENR-P1 and CTS-g-ENR$\mathrm{P} 2$ are illustrated in Figure 7. Two cycles of heating and cooling runs were carried out in order to eliminate the moisture effect, and the temperature region was taken into consideration to avoid thermal degradation in the first heating. The $T_{\mathrm{g}}$ of CTS/ENR50control, sample prepared by physically mixing appropriate amounts of CTS and ENR50, was found to be $-27.24^{\circ} \mathrm{C}$. This $T_{\mathrm{g}}$ is very close to that of ENR 50 $\left(-23.90^{\circ} \mathrm{C}\right)$, indicating no reaction took place under this condition. The $T_{\mathrm{g}}$ of CTS is not observed in Figure 7 because it occurred at a higher temperature, $203^{\circ} \mathrm{C}$ [34], i.e., outside the temperature range indicated. The $T_{\mathrm{g}}$ of CTS-g-ENR-P2, the biocomposite obtained with the use of a lower concentration of $\mathrm{AlCl}_{3} \cdot 6 \mathrm{H}_{2} \mathrm{O}$, is $2.88^{\circ} \mathrm{C}$. The fact that only one $T_{\mathrm{g}}$ was detected for CTS-g-ENR-P2 exemplify a new product that had formed arising from the grafting of CTS onto the backbone ENR50. The $T_{\mathrm{g}}$ of CTS-gENR-P1, the biocomposite obtained with the use of a higher concentration of $\mathrm{AlCl}_{3} \cdot 6 \mathrm{H}_{2} \mathrm{O}$, is also not

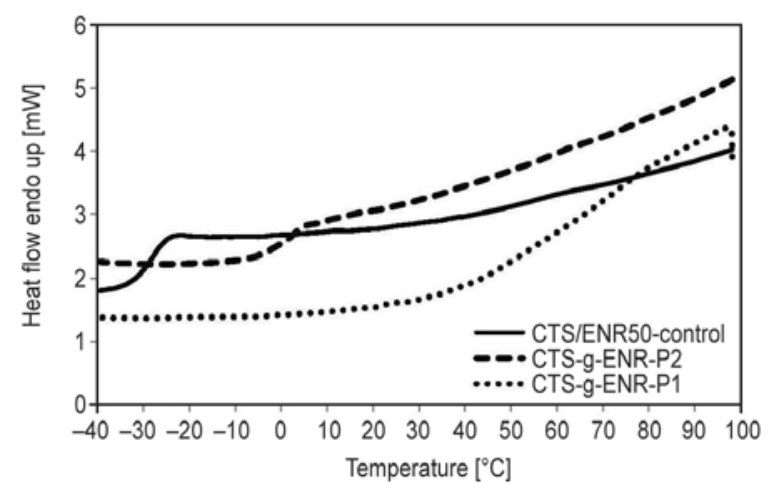

Figure 7. DSC curves of the CTS/ENR50-control, CTS-gENR-P1 and CTS-g-ENR-P2 observed in Figure 7 because it is closer to that of CTS which occurred outside the temperature range indicated.

\subsection{Thermogravimetric analysis}

The thermogravimetric (TGA) and derivative thermogravimetric (DTG) curves of ENR50, CTS, CTSg-ENR-P1 and CTS-g-ENR-P2 are depicted in Figure 8 and Figure 9, respectively. The DTG curve of ENR50 exhibits one-step degradation process with rapid weight loss of $48 \%$ at $418^{\circ} \mathrm{C}$. The major mass loss occurred within 310 and $570^{\circ} \mathrm{C}$ is $96 \%$ due to the total pyrolysis (decomposition of the hydrocarbon in nitrogen atmosphere) of the rubber matrices. The amount of carbonized residue deduced from the TGA curve of ENR 50 beyond $600^{\circ} \mathrm{C}$ is about $2.5 \%$. DTG curve of CTS exhibits mass loss at two stages. The initial mass loss of $12 \%$ occurred within 40 and $240^{\circ} \mathrm{C}$ due to loss of solvent molecules (water and acetic acid). The second stage shows a mass loss of $52 \%$ within 240 and $400^{\circ} \mathrm{C}$ due to degradation (via chain scission) of CTS [35]. The amount of carbonized residue deduced from the TGA curve of CTS beyond $600^{\circ} \mathrm{C}$ is about $33.8 \%$ which is quite substantial compared to that of ENR50. However, from the view point of thermal stability it is of interest to note that within 270 and $340^{\circ} \mathrm{C}$ only about $1 \%$ of ENR50 degraded whereas CTS degraded by about $38 \%$. Therefore, ENR50 is thermally more stable than CTS.

Both DTG curves of CTS-g-ENR-P1 and CTS-gENR-P2 show approximately similar three degradation stages. The first mass loss of $3 \%$ occurred within 40 and $150^{\circ} \mathrm{C}$ attributable to solvent molecules (water and 1,4-dioxane) imbedded in the biopolymers. The second mass loss of $15 \%$ occurred within 140 and $300^{\circ} \mathrm{C}$ due to the destruction of amino

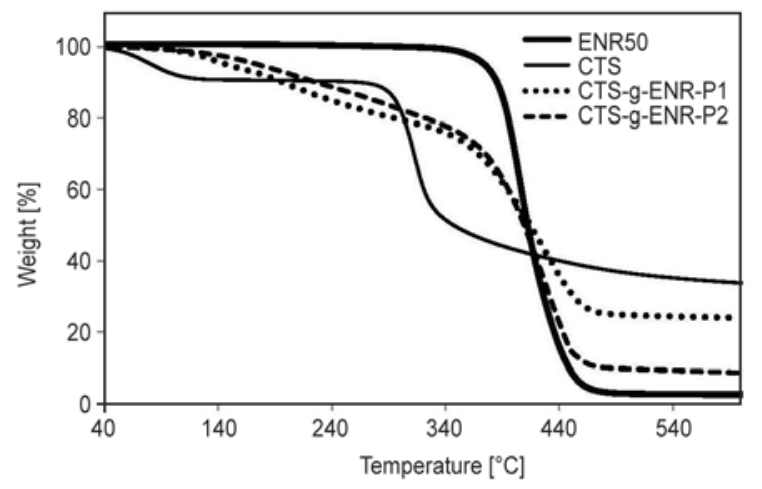

Figure 8. TGA curves for ENR50, CTS, CTS-g-ENR-P1 and CTS-g-ENR-P2 


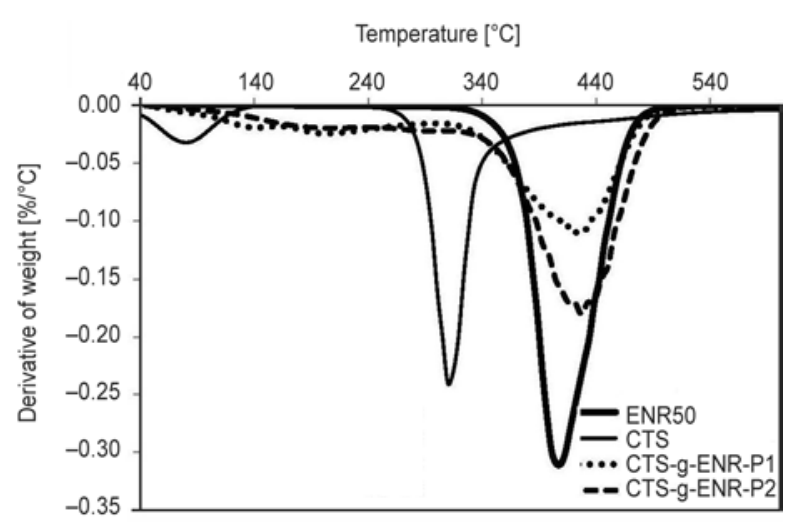

Figure 9. DTG curves for ENR50, CTS, CTS-g-ENR50-P1 and CTS-g-ENR50-P2

groups of CTS [9]. The third is the major mass loss of $56 \%$ occurred within 300 and $594^{\circ} \mathrm{C}$ due to a combination of chain scission of the grafted CTS and total decomposition of the rubber matrices. The amount of carbonized residue deduced from the TGA curves of CTS-g-ENR-P1 and CTS-g-ENR-P2 beyond $600^{\circ} \mathrm{C}$ is 24 and $9 \%$, respectively. Therefore, it is apparent that lesser amount of CTS incorporated (grafted) onto the rubber matrices resulted in a lower amount of carbonized residue beyond $600^{\circ} \mathrm{C}$. The thermal stabilities of CTS-g-ENR-P1 and CTS-


(iii)
g-ENR-P2 are quite similar and likely due to a combination of that of CTS and ENR50, i.e., higher than that of CTS but lower than that of ENR50.

\subsection{Morphology study}

SEM micrographs of CTS, ENR50 and CTS-gENR-P1 are shown in Figure 10. The chitosan has a flaky and uneven shape with smooth surface but the ENR50 displays a rough and groove like structure with some debris. Micrographs of the biocomposite show a one-phase morphology with a reduced gap between the chitosan and the rubber matrices suggesting not only good interfacial interactions but also very likely that CTS has been successfully grafted onto the backbone of the ENR.

\subsection{Reaction pathways for the formation of CTS-g-ENR biopolymers}

The plausible reaction pathways for the formation of CTS-g-ENR biopolymers are proposed in Figure 11. In a mildly acidic condition such as in solution containing $\mathrm{AlCl}_{3} \cdot 6 \mathrm{H}_{2} \mathrm{O}(\mathrm{pH}=4.5)$, the epoxidized isoprene units of ENR50 would likely be protonated and susceptible to attack by reactive nucleophiles. How-
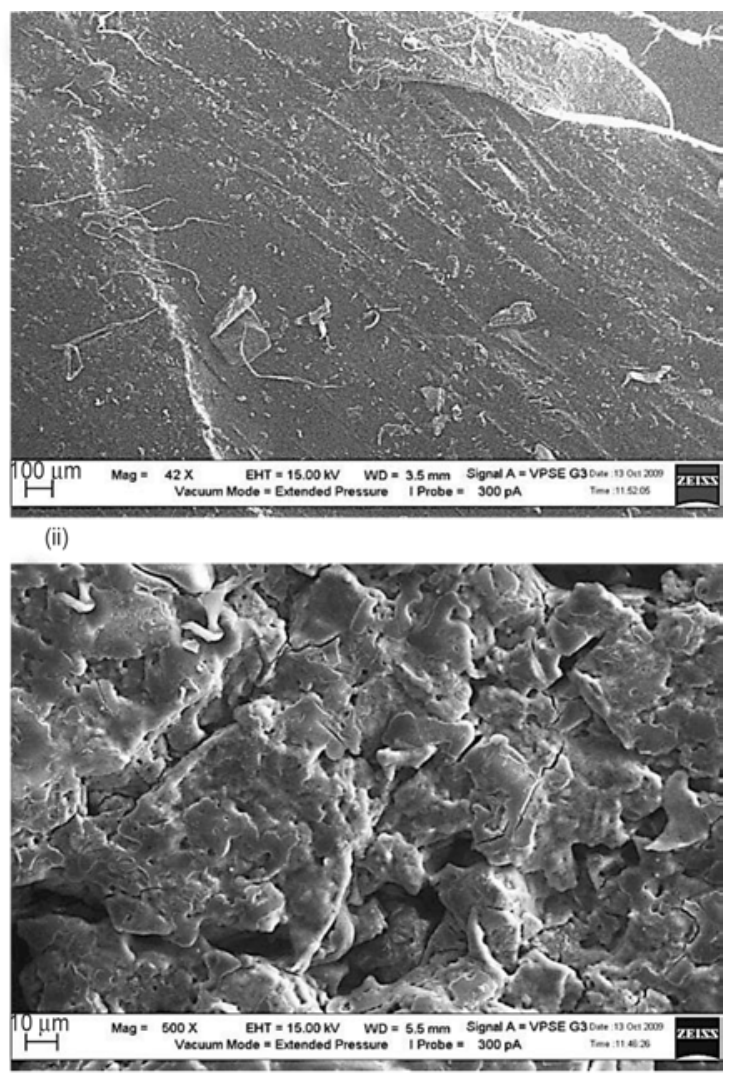

(iv)

Figure 10. SEM micrographs of (i) CTS, (ii) ENR50, (iii) CTS-g-ENR-P1 at magnification of 42×, (iv) CTS-g-ENR-P1 biopolymers at magnification of 500× 


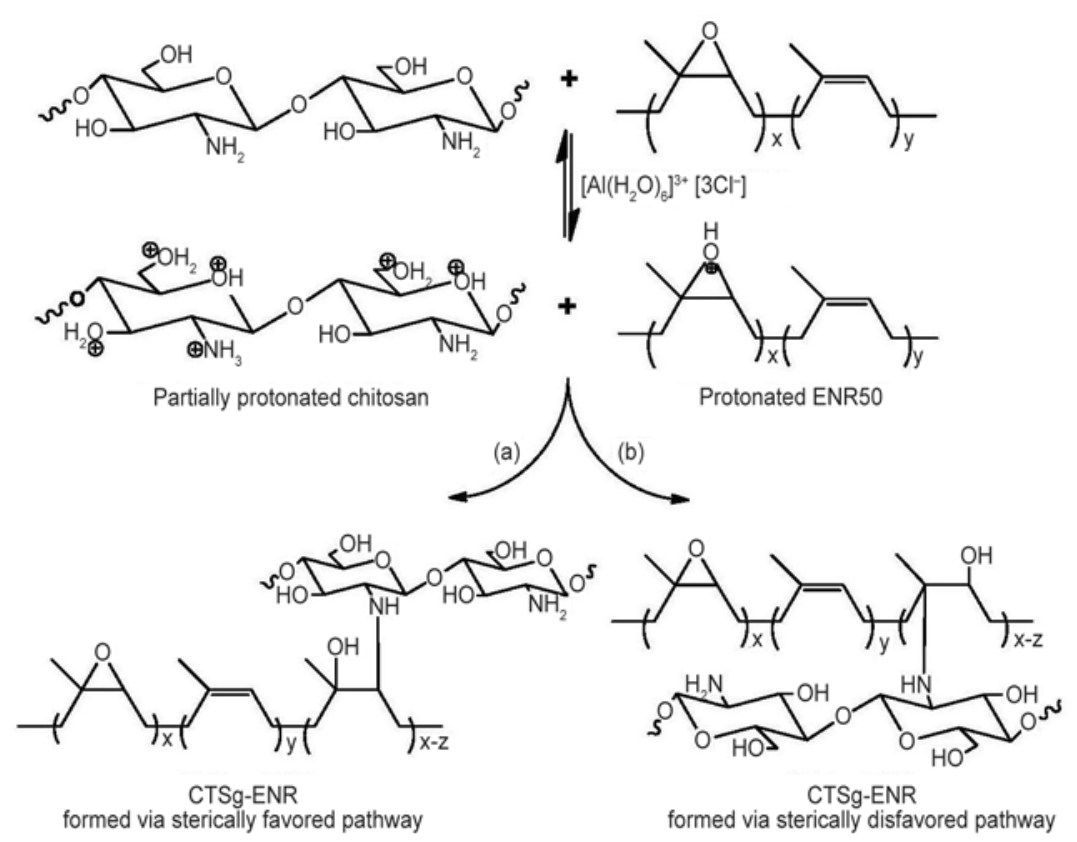

Figure 11. Reaction pathways for the formation of CTS-g-ENR biopolymers

ever under the similar mildly acidic condition, CTS being a multinucleophilic material would be partially protonated. The unhindered primary $(\mathrm{C}-6)$ hydroxyl group of CTS would be protonated rendering it non-reactive, whereas some of the sterically hindered primary amino (C-2) and secondary (C-3) hydroxyl groups would be free, i.e., remain as reactive nucleophiles. A primary amino group is much more reactive than a secondary hydroxyl group. As such, the grafting of CTS onto the backbone of ENR50 would involve solely the attack of the primary amino (C-2) of CTS on the protonated epoxidized isoprene units of ENR50. The attack may occur via sterically favored pathway (a) and sterically disfavored pathway (b) as illustrated in Figure 11. However, considering that CTS is a bulky polymeric entity and the fact that ENR50 remained structurally stable in the mildly acidic condition, we are of the opinion that the acid-induced reaction of ENR50 with CTS occurred preferentially or regioselectively via the sterically favored pathway. This notion is further supported by the infrared spectral analysis described above.

\section{Conclusions}

The effect of acidity on the stability of the molecular structure of ENR50 was investigated. It is hitherto elucidated by means of NMR spectroscopy that ENR50 remained structurally stable in 1,4-dioxane acidified by the addition of dilute $\mathrm{HCl}$ or
$\mathrm{AlCl}_{3} \cdot 6 \mathrm{H}_{2} \mathrm{O}$ solution. Based on this finding, the acid-induced reaction of ENR50 with CTS in a dual-solvent consisting of 1,4-dioxane and water $(97.5: 2.5 \% \mathrm{v} / \mathrm{v})$ was explored. Two type of biopolymers CTS-g-ENR-P1 and CTS-g-ENR-P2 consisting of higher and lower amount CTS, respectively, grafted onto the backbone on the natural rubber derivative were prepared. The structural and physicochemical properties of the products as compared to that of the starting materials were characterized by means of FT-NMR, FT-IR, SEM, DSC and TGA techniques. The regioselectivity of the acid-induced reaction is discussed and it is concluded that the biopolymers were formed via sterically favored pathway involving the attack of the primary amino (C-2) of CTS on the protonated epoxidized isoprene units of ENR50.

\section{Acknowledgements}

The authors would like to thank the Malaysian Government and Universiti Sains Malaysia for providing the financial support via the Fundamental Research Grant Scheme (FRGS) No. 1001/PKIMIA/842021. They would like to also extend their deepest gratitude to Dr Kartini Noorsal from Advanced Materials Research Centre (AMREC), Kulim for her assistance in providing the SEM facilities.

\section{References}

[1] Muzzarelli R.: Chitin. Pergamon Press, Oxford (1977).

[2] Chandra R., Rustgi R.: Biodegradable polymers. Progress in Polymer Science, 23, 1273-1335 (1998). DOI: $\underline{10.1016 / \mathrm{S} 0079-6700(97) 00039-7}$ 
[3] Auzély R., Rinaudo M.: Controlled chemical modifications of chitosan. Characterization and investigation of original properties. Macromolecular Bioscience, 3, 562-565 (2003).

DOI: $10.1002 / \mathrm{mabi} .200300018$

[4] Dutta P., Dutta J., Tripathi V.: Chitin and chitosan: Chemistry, property and application. Journal of Scientific and Industrial Research, 63, 20-31 (2004).

[5] Munro N. H., Hanton L. R., Moratti S. C., Robinson B. H.: Preparation and graft copolymerisation of thiolated $\beta$-chitin and chitosan derivatives. Carbohydrate Polymers, 78, 137-145 (2009).

DOI: $10.1016 /$ j.carbpol.2009.04.018

[6] Muzzarelli R. A. A., Muzzarelli C.: Chitosan chemistry: Relevance to the biomedical sciences. in 'Polysaccharides I' (ed.: Heinze T.) Springer, Berlin, 151209 (2005).

DOI: $10.1007 / \mathrm{b} 136820$

[7] Rogovina S. Z., Alexanyan C. V., Prut E. V.: Biodegradable blends based on chitin and chitosan: Production, structure, and properties. Journal of Applied Polymer Science, 121, 1850-1859 (2011).

DOI: $10.1002 / a p p .33477$

[8] Johns J., Rao V.: Characterization of natural rubber latex/chitosan blends. Journal of Polymer Analysis and Characterization, 13, 280-291 (2008).

DOI: $10.1080 / 10236660802190104$

[9] Rao V., Johns J.: Mechanical properties of thermoplastic elastomeric blends of chitosan and natural rubber latex. Journal of Applied Polymer Science, 107, $2217-$ 2223 (2008).

DOI: $10.1002 / a p p .27265$

[10] Rao V., Johns J.: Thermal behavior of chitosan/natural rubber latex blends TG and DSC analysis. Journal of Thermal Analysis and Calorimetry, 92, 801-806 (2008). DOI: $10.1007 / \mathrm{s} 10973-007-8854-5$

[11] Johns J., Rao V.: Mechanical properties and swelling behavior of cross-linked natural rubber/chitosan blends. International Journal of Polymer Analysis and Characterization, 14, 508-526 (2009).

DOI: $10.1080 / 10236660903072797$

[12] Johns J., Rao V.: Thermal stability, morphology, and $\mathrm{X}$-ray diffraction studies of dynamically vulcanized natural rubber/chitosan blends. Journal of Materials Science, 44, 4087-4097 (2009).

DOI: $10.1007 / \mathrm{s} 10853-009-3589-2$

[13] Letwattanaseri T., Ichikawa N., Mizoguchi T., Tanaka Y., Chirachanchai S.: Epoxidized natural rubber bionanocomposite: A model case of bionanocomposite using nanofibrous chitosan and its consequent functional properties. Chemistry Letters, 38, 798-799 (2009).

DOI: $10.1246 / \mathrm{cl} .2009 .798$

[14] Shaari S., Ismail H., Othman N.: The effect of chitosan loading on the properties of chitosan filled epoxidized natural rubber compounds. Key Engineering Materials, 471-472, 851-856 (2011).

DOI: 10.4028/www.scientific.net/KEM.471-472.851
[15] Ismail H., Shaari S. M., Othman N.: The effect of chitosan loading on the curing characteristics, mechanical and morphological properties of chitosan-filled natural rubber (NR), epoxidised natural rubber (ENR) and styrene-butadiene rubber (SBR) compounds. Polymer Testing, 30, 784-790 (2011).

DOI: $10.1016 /$ j.polymertesting.2011.07.003

[16] Riyajan S-A., Sukhlaaied W.: Effect of chitosan content on gel content of epoxized natural rubber grafted with chitosan in latex form. Materials Science and Engineering: C, 33, 1041-1047 (2013). DOI: $10.1016 /$ j.msec.2012.11.012

[17] Ravi Kumar M. N.: A review of chitin and chitosan applications. Reactive and Functional Polymers, 46, 1-27 (2000). DOI: $10.1016 / \mathrm{S} 1381-5148(00) 00038-9$

[18] Aranaz I., Mengibar M., Harris R., Panos I., Miralles B., Acosta N., Heras A.: Functional characterization of chitin and chitosan. Current Chemical Biology, 3, 203230 (2009).

DOI: $10.2174 / 187231309788166415$

[19] Gelling I., Tinker A., Rahman H. B.: Solubility parameters of epoxidised natural rubber. Journal of Natural Rubber Research, 6, 20-29 (1991).

[20] Gelling I.: Epoxidised natural rubber. Journal Rubber Research, 6, 184-205 (1991).

[21] Derouet D., Brosse J-C., Challioui A.: Alcoholysis of epoxidized polyisoprenes by direct opening of oxirane rings with alcohol derivatives 1 . Modelization of the reaction. European Polymer Journal, 37, 1315-1326 (2001).

DOI: $10.1016 / \mathrm{S} 0014-3057(00) 00266-4$

[22] Derouet D., Brosse J-C., Challioui A.: Alcoholysis of epoxidized polyisoprenes by direct opening of oxirane rings with alcohol derivatives 2 . Study on epoxidized 1,4-polyisoprene. European Polymer Journal, 37, 1327-1337 (2001).

DOI: $10.1016 / \mathrm{S} 0014-3057(00) 00267-6$

[23] Gan S-N., Abdul Hamid Z.: Partial conversion of epoxide groups to diols in epoxidized natural rubber. Polymer, 38, 1953-1956 (1997).

DOI: $10.1016 / \mathrm{S} 0032-3861(96) 00710-0$

[24] Derouet D., Brosse J., Tillekeratne L.: Fixation of methacrylic acid onto epoxidised liquid natural rubber. Journal of Natural Rubber Research, 5, 296-300 (1990).

[25] Jayawardena S., Rexy D., Durand D., Pinazzi C. P.: Synthesis of macromolecular antioxidants by reaction of aromatic amines with epoxidized polyisoprene, 3 . Reaction of 4-anilinoaniline with epoxidized 1,4-polyisoprene. Die Makromolekulare Chemie, 185, 20892097 (1984). DOI: $10.1002 / \mathrm{macp} .1984 .021851004$

[26] Siti Maznah K., Baharin A., Hanafi I., Azhar M. E., Mas Rosemal Hakim M. H.: Effect of soaking in potassium hydroxide solution on the curing, tensile properties and extractable protein content of natural rubber latex films. Polymer Testing, 27, 1013-1016 (2008). DOI: $\underline{10.1016 / j . p o l y m e r t e s t i n g .2008 .09 .005}$ 
[27] Siti Maznah K., Baharin A., Hanafi I., Azhar M. E., Rosemal Hakim M. H.: Effect of acid treatment on extractable protein content, crosslink density and tensile properties of natural rubber latex films. Polymer Testing, 27, 823-826 (2008).

DOI: 10.1016/j.polymertesting.2008.06.004

[28] Lu S., Song X., Cao D., Chen Y., Yao K.: Preparation of water-soluble chitosan. Journal of Applied Polymer Science, 91, 3497-3503 (2004).

DOI: 10.1002/app.13537

[29] Saito T., Klinklai W., Kawahara S.: Characterization of epoxidized natural rubber by 2D NMR spectroscopy. Polymer, 48, 750-757 (2007).

DOI: $10.1016 /$ j.polymer.2006.12.001

[30] Malz F., Jancke H.: Validation of quantitative NMR. Journal of Pharmaceutical and Biomedical Analysis, 38, 813-823 (2005).

DOI: $10.1016 /$ j.jpba.2005.01.043

[31] Mahmood W. A. K., Khan M. M. R., Azarian M. H.: Sol-gel synthesis and morphology, thermal and optical properties of epoxidized natural rubber/zirconia hybrid films. Journal of Non-Crystalline Solids, 378, 152 157 (2013).

DOI: $10.1016 /$ j.jnoncrysol.2013.07.002
[32] Duan K., Chen H., Huang J., Yu J., Liu S., Wang D., Li Y.: One-step synthesis of amino-reserved chitosangraft-polycaprolactone as a promising substance of biomaterial. Carbohydrate Polymer, 80, 498-503 (2010). DOI: $10.1016 /$ j.carbpol.2009.12.013

[33] Ng L-T., Swami S.: IPNs based on chitosan with NVP and NVP/HEMA synthesised through photoinitiatorfree photopolymerisation technique for biomedical applications. Carbohydrate Polymers, 60, 523-528 (2005).

DOI: 10.1016/j.carbpol.2005.03.009

[34] Sakurai K., Maegawa T., Takahashi T.: Glass transition temperature of chitosan and miscibility of chitosan/poly ( $N$-vinyl pyrrolidone) blends. Polymer, 41, 7051-7056 (2000). DOI: $10.1016 / \mathrm{S} 0032-3861(00) 00067-7$

[35] Pawlak A., Mucha M.: Thermogravimetric and FTIR studies of chitosan blends. Thermochimia Acta, 396, 153-166 (2003).

DOI: $10.1016 / \mathrm{S} 0040-6031(02) 00523-3$ 